\title{
Change of Music in the Internet Age and Its Reasons Research
}

\author{
Jiaran Ding \\ College of Music, Jiangxi University of Technology
}

Keywords: The Internet Age; Network songs; Music dissemination; Music creation; Folk discourse power

\begin{abstract}
Music in the Internet Age has changed in communication, creation, artistic style and aesthetic value orientation, and these changes are the product of the development of the modern era, they are the result of science and technology progress, the social and economic development and people's ideological change. Music communication in the Internet Age not only has overcome the shortcomings in natural transmission time (i.e., the original form of communication), such as narrow communication range and fuzzy communication effect, but also has overcome the limits of both sides isolated, being passive and limited in the traditional communication age, which consolidated and developed the advantages of the two. The most direct embodiment of the music creation's change in the Internet Age is the birth and the popularity of the network songs. Network songs refers to these songs that are created, spread, and become popular through the network. Network song is an entertainment of netizens, the real emotional expression of civilian and a return to the folk music discourse power; and its aesthetic taste trends to interest; network song has its existence rationality, in which the refraction of the social problem is also worth our reflection, and it has positively warning effects on the socialist construction; but there are also negative effects about network songs: the too rebellious God and the contents which are misleading for children and adolescents. It is a problem calls for the concern of the whole society to let the network songs get rid of the two difficult situation.
\end{abstract}

\section{Introduction}

April 20, 1994, China officially accessed to the international Internet and opened the network and provided comprehensive services to the community in May 1995. From then on, China has entered the Age of Network Information whose arrival has brought a huge change to Chinese society. There were a series of earth shaking changes in the way people work, contact information, access to information, consumption, and so on. Emerging industry also emerged endlessly, and the Internet storm swept the various industries. Music, as an important social and cultural pattern, absolutely can't escape from the baptism of the storm. Music in the Internet Age are different from the past music forms regardless of its creation, dissemination, appreciation, marketing or the fame of composers or singers, and even the evaluation of the music values. In addition, there are articles on the problem of the increment of network music, network music industry and so on, such as the online music how to break through the value "chain", music industry situation analysis in the digital music era etc. In summary, the researches about network music are mostly focused on the technical level of the dissemination, the copyright problem and industrial added value of network music at present.

It is controversial about the current network song which majorly surrounds that whether its content is healthy or vulgar. There is no elegant or vulgar, no good or bad, no beautiful or not 
beautiful for the music itself, these standards are formulated by the aesthetic subject in the specific historical and cultural environment, therefore, we should research the network songs' rise, popularity, content, style and so on under the current backgrounds. Throughout the history of the development of music at all times and in all over the world, the emergence, development, prosperity and decline of any form of music, music style, music phenomenon cannot be divorced from the historical and cultural background of the society at that time and exist independently. Not considering the problems about society, psychology, video, ritual, technological history, economy, linguistic and culture which are closely related to the audio features, style, function, style, performance situation of pop music, any research on popular music is partial and insufficient. Simon Frith is the core characters of pop music research who has a far-reaching impact on the research of western pop music, whose research is often set sociology, anthropology, economics, music, literature, history and philosophy research in one. He believes that pop music is a conversation related to the values, understanding and consultation to solve divergence, which is about identity, about how people live a life in the world and reconstruct the world.

\section{The reasons for the changes of music in the Internet Age}

It is still inconclusive and needs continual exploration when music origin exactly. But it depends entirely on the music dissemination activities for different forms of music, music variety and different genre featured music works to continue right up until the present day with respect to thousands of years of human's developing history. The appearance of the music score has overcome the ambiguity of the dissemination effect in a certain degree, and as the earliest music medium, it has opened the door to the technological spread.

With the rapid development of computer technology and Internet technology, human society entered the Internet Age. Music communication in the Network Age, which has unmatched advantages compared to traditional means of communication, not only combines the advantages of all the traditional communication technology, but also breaks through many limitations of it.

Only the talents in singing songs or playing music may become the subject of communication in the era of natural communication; In the era of the traditional technological communication, if you want to be a music disseminating person (either to set up a record company to release the album or to establish a radio station or television station), you are not only limited by the industrial technology, but also need the approval of relevant departments of the state. In the Internet Age, it is that the communication subjects of all sorts and different natures who brings rich musical resources to the cyberspace for different purposes making it possible to find the needed resources in the musical technological websites for both the ones professionally engaged in musical learning and work and amateurs.

In the era of network communication, the recipients absolutely enjoy the VIP service. Here, every recipient's personality is fully respected and independence gets into full play, which is really the "God" - like courtesy.

If the progress of communication technology of music is just music works draw support from the inventions of science and technology as a medium of communication, still not be real rendezvous "science and art", so the electronic music which is taken part in directly by the science and technology in the creation process is the perfect blend of music and science in "shape" and "spirit". Music is a kind of non-semantic and non-visual art, therefore, so it is very difficult to present emotional, visual especially cognitive objectives accurately, the composers can only imitate or show 
some characters of what he wanted to express by the tone of permutation and combination of movement, interval structure and playing skills (singing skills) of different instrument timbre (or voice).

In the era of Internet communication, the music creation thinking of the contemporary musicians will be broader and the language of music will be richer. The immediacy and interactivity of network dissemination make the music communication start at the moment that composers finished the work and released it to the Internet. At the same time, any one has the feelings, opinions and suggestions can communicate and exchange ideas with the composers, which may lead composer in a new creative sparks and further enrich the language of music. The democracy of the Internet makes anyone can participate in it, anyone can theoretically conduct music creation and express their feelings.

This is an era of national entertainment, with work competition and the survival pressure surging, entertainment has become essential in the life as the valve and lubricant. People's leisure time is filled with all kinds of fast food culture full of entertainment and vent, which are stimulating people's visual and auditory nerve. From Kongfu novels to romance novels, from the sci-fi blockbuster to life sitcom, from the secret history of the court drama to country love...... Entertainment is getting closer to the people's life and pay more and more attention to the public's emotion. From the Avenue of Stars to Dream Theater, from Super Girls to Happy Boys, various entertainment show upgrade again and again and emphasis more and more on public participation.

However, not everyone has the time and energy to walk on CCTV's Avenue of Stars and Dream Theater, and not everyone has the conditions and opportunities to become a super girl or happy boy. More people have to be busy with work for a living, only gossip a little leisure time; more people are plain in appearance, no star qualification. Openness, democracy and tolerance of network provides a better platform for mass entertainment where is regardless of age, gender, identity and appearance: there is no strict access mechanism, no harsh requirements, no complex rules and limits; no requirements from sponsors, no little fingers of judges, no deliberately plan and arrangement of program group... Here is just entertainment, no need to please anyone, no interest involved, and pure, real, folk entertainment.

Because the network song is a way for netizens to entertain themselves, so its creation community must be part of the netizens whose overall characteristics is high knowledge level and low age. The survey results about China's information industry which conducted by Countries Information Industry Department of Electronic Information Center and Lantian Market Research Firm recently show that currently the netizens are mainly young people, the vast majority is under 35 years old, and high school education is netizens' lowest degree. (1)Therefore, the creation group of the network song presents the characteristic of youth. The virtual nature of network makes the network composer and network singers are very covert, it is often that a network song became popular for a long time, but netizens do not know the singer's Mount Lu true colors.

Network song lyrics which are informal and filled with colloquialism are easy to understand, the theme is daily life and the people related, and the expression is the true feelings of the people.

From the song lyric of the network songs, it can reflect the aesthetic value of the network songs to the most. Recalling the network from the birth at the beginning to now, the lyrics of every network song get popular are embodied with entertainment selling points.

In addition, many network song lyrics directly reflects the color of the science and technology in the information age, such as I want to call you/ let all the hotline to convey my love / I want to stand 
up in the highest roof of the city / that the signal of love will no longer be blind in the Glorious Second Street, click on your name/ send you happy in the Network Love. It takes the proper nouns and network terminology of information age directly into the lyrics of network songs whose aesthetic value orientation is embodied a kind of aesthetic taste of the public, or common interest.

Common interest is a correspondence to the elegant interest. "Generally speaking, elegance is mastered by the individual group and characters, and forms a strict standard of art, inner aesthetic norms as well as independent style system after the washing of aesthetic vision for generations, namely the interest reflected by the so-called elite culture and entitlement culture, known as elegance. It conveys the emotion and will of the ruling class, so there is a strict, normalization, and most looked solemn, implicit and complex, which makes it difficult for the general public to close. But the general populace's interest then is oppositely inclined to the vulgar. The so-called secular, that is, the meaning of the public. It comes directly from the life of ordinary people, full of daily life breath, and presents barely the desire of all kinds of life. It has no strict standards and it is straight, bold, and vulgar."

From the music to the lyrics text, from the subject matter to the performance technique, the network song reflects the populace's esthetic interest. Even the political or patriotic theme, it is no longer take use of the national discourse with the elegant solemn gesture, but to adopt an easy and enjoyable rap way. The aesthetic value orientation of network songs is the production of social music.

The embodiments of natural characteristic in current society. Network music is a kind of self-enjoyment of the netizens, a spirit of relaxation, and it's the best chance for human's music given by industrial society's high technologies to go down the altar and return to the folk discourse power, the last habitat for spirit. However, the final spiritual habitat is now facing a hard situation. Network song is an entertainment form of ordinary people, so gameplay and entertainment bear the brunt of becoming its purpose. Under this purpose, all subject matters and themes are relaxed, pleased, humorous and funny. Even the themes showing the sufferings of people or the patriotic themes will not give up adding some entertainment elements, and the spirits of teasing, criticism, ridicule, the subversion are manifested everywhere. It is no doubt that this aesthetic value pursuit of network songs has positive effects on easing people's psychological anxiety, giving vent to people's daily pressure, but if the game spirit and rebellious spirit get popular and become the social mainstream culture, it will indeed produce an extremely bad influence on the growth of children.

The economic development is the important of the change of music communication in the Internet Age. With the development of the economy, people's living standards has greatly enhanced and the purchasing ability has substantially increase. The computer, MP3, musical mobile phone and other high-tech products are consumed by more and more ordinary people. Only with these carriers, the changes in music communication in the Internet Age can be achieved. Similarly, people will pursue the spiritual needs of a higher level only after the basic human material life guaranteed with the development of economy. The economic development not only provides material premises for the music communication in the Internet era, the competition mechanism of the market economy and the service concept which are introduced into Internet music sales, are also important economic factors contributing to the position changes of both sides in the music dissemination of Internet era. In marketing economy era, the most commonly used industrial slogans in sales industry and service industry are: high quality and inexpensive; cheap and fine; the customer is the God......, a variety of 
websites in any sizes thoroughly implemented the traditional concept that the customer is God in order to seek their own development in the increasingly fierce competition.

This change in the music creation in the Internet era is determined by the Internet's spreading characteristics, so there is a lot in common between the causes music creation's change and the reasons for the changes of music in the Internet Age. The changes of music creation in the Internet Age are also the results leaded by the progress of the science and technology, the development of social economy and the human's ideological changes. It has been analyzed in detail in the first section of this chapter about the technical support provided by the progress of science and technology and the material premise provided by social and economic developments, this will not repeat them.

It is fundamentally decided by the characteristics of its own that the music phenomenon of the network songs can be popular. Network songs are created, spread and get popular through the network. In other words, the reasons for network song becoming so popular are it is unaffected and does not gloss over the reality. It is people's real emotional expression about life, is the contemporary folk song cloaked in the high-techs, and is a return to the folk music discourse power. Similarly, business of adding fuel to the flames is also a crucial factor contributed to the network songs' popularity. As it goes in the articles discussing popular songs "popular songs own popular" (4), it is the result of joint action of the above all sorts of reasons for the network songs getting popular.

\section{Conclusions}

With the progress of Internet technology, the development society and economy and enhancing consciousness of people's pursuing for personality, democracy and equality, the music in the era of the Internet media indeed has a great progress in many ways than that in the traditional media era. It is the low threshold of Internet access mechanism that makes music communication subject more diverse, the dissemination of the contents more abundant, and more convenient to obtain music resources for the recipients, the receiver can be free to choose their own music resources that they love and need. One of the result is that the creators of the music have achieved great liberation and the music creators can exert their musical ideas without interference of inartistic factors; the interaction between disseminator and receiver will further expand the musicians' creative ideas and enrich the musical language. It is especially musicians around the world communicating online that makes it possible for the communication, learning and fusion among the world music languages, which will produce a large number of more excellent musical works. The openness, freedom, equality, and democracy of Internet makes everyone here can express their ideas freely, show their talent and find their own "bosom friend", it is the mechanism of the low access let the network singers and network songs appear. Network songs present the daily joys and sorrows ordinary people with popular tunes and colloquial lyrics, which embodies the aesthetic value orientation of the public. Therefore, it takes a heavy burden and embark on a long road to correctly handle the relationship between network songs' function of entertaining spirits, giving vent to pressure and the function of developing commercial economy, nurturing social morality. 


\section{References}

[1] [Germany J Sargent - Kleinen etc., translated by Jin Jingyan. Music education and sociology of music [M]. Beijing: Central Conservatory of Music Press, 2008.

[2] Jia Ke - Adali, translated by Song Sufeng, Weng Guitang. Noise: political economy of music [M]. Shanghai People's Press, 2000.

[3] Kenev, etc., translated by Jin Jingyan. Sociological Status of Western Music [M]. People's Music Press.2000.

[4] Zeng Suijin. Musical sociology [M]. Shanghai: Shanghai Conservatory of Music Press, 2004.

[5] The Education Department of Shandong province. The Cultural Foundation of Computer [M]. Petroleum University Press, 2002.

[6] Zhou Haihong. The World of Music and Its Performance - Psychological and Aesthetical Research between the Music and Its Objects. [M]. Beijing: Central Conservatory of Music Press, 2004.

[7] Liu Zaisheng. Brief History of Chinese Ancient Music [M]. Beijing: People's Music Press, 1989.

[8] [American] Stephen Beisite, Douglas Kellner, translated by Chen Gang, etc. The Postmodern Turn [M]. Nanjing: Nanjing University Press, 2002.

[9] Yin Hong, etc. Entertainment Whirlwind - To Recognize the TV Reality Show [M]. Beijing: China Radio Press, 2006.

[10] Xu Wenyu, Zhu Yuanzhong, Xu Miaomiao, etc. Criticism on Public Culture [M]. Capital Normal University Press, 2002. 